\title{
Study on Innovative Talent Education Model for Electrical Engineering Major
}

\author{
Duoying Zhang, Wanling Deng*, Junkai Huang, Xiaoyu Ma \\ Department of Electronic Engineering \\ Jinan University \\ Guangzhou 510630, China \\ *E-mail: dwanl@126.com
}

\begin{abstract}
With the current urgent needs of high quality innovative engineering talents for electronic and information industry, innovative talent education and training models are becoming more and more important. In this paper, the model of cultivating diversified and application-oriented engineering talents is studied. Furthermore, the plan for the optimization of the curriculum and practical training is discussed. Also, the practical education mode, in form of industrial cooperation, innovative competitions and virtual labs, is studied for the creative engineering talents.
\end{abstract}

Keywords-innovative talents; education; model; electrical engineering major

\section{INTRODUCTION}

As China has become the world's second largest economy, the comprehensive industrial cost rises, and the demographic dividend disappears. Now, our country is changing from the resource-driven to efficiency-driven and innovation-driven country, as shown in Fig. 1. However, the proportion of highlevel innovative talents in our country is far behind the United States, Japan and other developed countries. There is a lack of high-level innovative engineering talents in the emerging industries, particularly in the electrical engineering (EE) industry. Therefore, in order to meet the urgent needs of the innovative development of our country, we must accelerate to explore the education model for the innovation engineering talents [1].

The scale of college students in our country is the largest in the world, but there is a disconnection between our higher engineering education and industry demand for the talents. In general, the engineering capability and quality of the graduates cannot meet the requirements of employers. In this background, as the education workers for the electronic information science, we must clearly recognize that the drawbacks of the traditional education model for the EE major, which has its evident industrial and social characteristics. The traditional model builds an "assembly line" for education, but makes an obstacle to improve students' overall level of innovation. It shapes the engineering talents with a single mode, which obstructs the development of creativity. Therefore, it is unable to meet the new requirements of the higher engineering education which is suitable for the emerging industry development. Thus, in this paper, we demonstrate the above-mentioned drawbacks and try

This work was supported in part by the Guangdong Higher Education Reform Project under Grant GDJG20141030, in part by the Jinan University Teaching Research Project under Grant JG2014032, in part by the Jinan University Postgraduate Teaching Reform Project under Grant 51000223, and in part by Guangdong Province Teaching Quality and Reform Project. to find solutions to the problems.



Fig.1. Simplified diagram of innovative industry development.

\section{Optimization of EE MaJor Training PROGRAM}

\section{A. Diversified Talent-Training Model}

Innovation is human-specific cognitive ability and practical ability. It is an advanced form of human initiative to promote national progress and social development of inexhaustible power. Innovation means change, pay and risk. It includes the ability to create imagination, the creative thinking, the ability to organize and implement certain activities, and the creative planning skills. In order to improve the level of innovation, an important way is the diversified talent-training model. Today's society is pluralistic. Social demand determines the type of individual training and education mode. Because cross-industry products and interdisciplinary applications become more and more common, the demand for talent is no longer a single type, but a multi-standard, multi-type, and multi-level one.

Course system reflects the framework of training and teaching mode. For the general education curriculum, it is suggested to optimize the structure of the basic, and account for the interdisciplinary combination [2]. For the elective courses, it is emphasized that the planning of courses accounts for the application of knowledge, culture and interdisciplinary 
expertise. Today's society is diverse, so the departments of university should provide students with a variety of course options. As a result, the students not only can accept a broad range of undergraduate training and find their interest in learning, but also realize their ability in learning. The interdisciplinary study is also conducive to the cultivation of students' innovative thinking.

In Fig.2, as an example of the department of Engineering and System Science in National Tsing Hua University, the specialized elective courses are divided into two parts, i.e., "academic expertise" and "applications". According to the research direction of the department, the "academic expertise" has four learning programs. Students can choose one of the listed programs and finish the requirement of the program. It focuses on training students with the basic theoretical knowledge within that research field. It is also recommended students to complete two or more academic expertise according to their ability. The "applications" is divided into Groups I and II. Each group is subdivided into two areas. Therefore, they have A, B, C, D application areas. "Applications" emphasizes cultivating students' practical ability and engineering capabilities. Students choose the application areas according to their interests, and also according to their own future, which means the desired research field when pursuing graduate studies. In addition, they can select one or more areas to meet the credit requirements. When students select one area, the department gives them a course map which clearly tells students the courses in each school year, from freshman to senior. In addition to offering a full range of curriculum choices, the case study discussions, book/paper discussions, and other flexible forms of study, are also provided for students to acquire the ability to solve practical engineering problems.

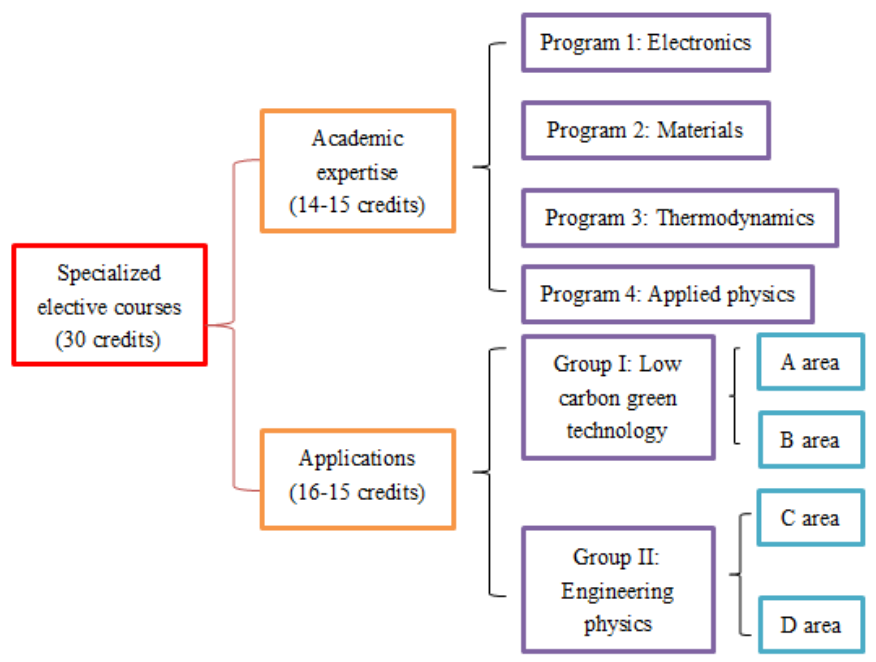

Fig.2. Simplified block diagram of the diversified elective courses.

This diversified course program is mainly to provide students a clearer direction and more detailed and specific learning curriculum. Students have more choices, and make the study become more specialized. The training planning in Fig. 2 proposes a concept, namely the robust " $\pi$ talent". It means this new talent has an in-depth knowledge in a professional field and becomes an expertise in another area, like two stable legs. In addition, he/she contacts a variety of disciplines and has a wide field of view, like the hand held flat. As depicted in Fig. 2, the different study plan, that is, different combination of program and area, can develop many interdisciplinary talents with different characteristics. The learning design of program pays more attention to the interdisciplinary knowledge, and avoids knowledge being divided into too small parts. Interdisciplinary teamwork has been an essential issue in today's society. Interdisciplinary knowledge and system integration capability help students to develop creativity. As a consequence, students have a solid competitive power.

\section{B. Individualized Education}

The personalized education is the exploration of potential of individual life and the education for free development of individual life with appropriate approaches. Human personality is based on the innate natural qualities. Therefore, individualized education is endless.

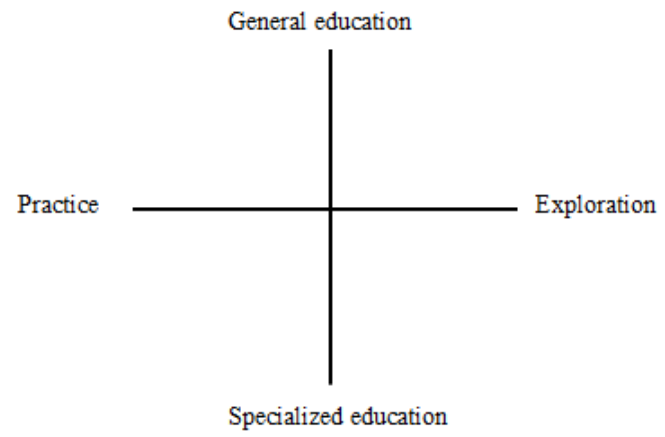

Fig.3. Two-dimensional image of higher education.

In the EE department of Jinan University, we have Tutorial System to give undergraduates guidance. This system is based on the concept of higher education with two-dimensional (2D) image. As shown in Fig.3, the traditional one-dimensional model includes general education and specialized education. Besides, the 2D image increases another dimension, i.e., practice and exploration. Thus, it can open up various possibilities of students, and help them to have the ability to explore the community and take action. In this process, the teacher aims at exciting the potential of each student with appropriate guide [3]. The university is committed to combine and provide the resources within and outside school. In this environment, through counseling, students think and discuss important social issues, participate in society care activities, and expand their life experience. The student should have the capability of independent thinking, program planning, execution, and spirit of cooperation. Through close contact with students, the tutor knows student's learning process, motivation, capability, and personality. Then the tutor guides them how to choose learning areas and research fields. They help student to design their own life and develop the interest in exploring the unknown world.

As teachers, in classroom or in life, we all need to encourage students to come out of their comfort zone, understand the society, experience the real problems of the world, and find or raise their concerns. Asking questions is always the first step to innovation. As teachers, we can guide students to propose meaningful social questions, or the 
problems of interest to students, which have the truly innovative power. With these problems, the next step is the process of solving problems, which is also the process of innovation. For undergraduates, there are a very small number of real innovations, but the universities or teachers encourage students to make mistakes. For the solutions to the problem, students are encouraged to put them into practice, even if unsuccessful. Unsuccess is acceptable or encouraged. Therefore, the training of innovative talents is also the training of identifying and solving problems.

\section{Practical Education Mode}

In our university, teachers are encouraged to use three types of teaching, namely innovative teaching, teaching creative ideas, and teaching entrepreneurship. The majority of students will leave school to enter social work, and therefore it is of great importance to have internships and practical activities. In the EE department of Jinan University, we have the "two tutors" system, i.e., one is academic tutor from university and the other is engineering tutor from enterprise. Relying on the undergraduate and postgraduate training programs, it focuses on the training of engineering practice and comprehensive ability. Also, it emphasizes potential and personality development, and builds a broad knowledge base to adapt the development of industry. Series of lectures are offered for all the students, such as Introduction to advanced technology by the well-known professors, the engineering lecture courses by the leading enterprise expert, introduction to starting business, etc. Various practical activities and internships are provided. One of them is the industrial practice, which is the internship with enterprises or companies [4]. Our department has established a long-term cooperation with Fenghua Advanced Tech. Holding Co. Ltd., Actions Semiconductor, and other hitech electronic enterprises. Another practice model is the participation in the research labs in the university. Moreover, students are encouraged to participate in the "National Electronic design Competition", the "Challenge Cup" competition and other extracurricular activities. Furthermore, they can improve the ability to cooperation through these practical activities.

An interactive simulation teaching platform is established, which is based on multiple-level practical teaching hardware and software. On the Internet or using the cloud-computing technology, students in dorms or anywhere at which they have a computer-like terminal, can enter the virtual labs and do some assignments or works. Software in virtual labs does not involve in the complex experimental processing, but it gives a clear view for the students about the working principle, the physical details inside the devices, the results of application, and so on [5]. Further, students can do much more than the things in books, and learn how to make their ideas and thinking into practices. The virtual labs make a connection between the academic teaching and the industrial applications. This is also an interacting platform, where teachers and students can communicate with each other. Further, teachers can manage and design their teaching materials in the database. On the other hand, students can share their learning experiences.

\section{CONCLUSIONS}

In order to develop truly innovative talents, training of engineering talents is a systematic project, throughout the higher education system. The optimization of education program for electrical engineering major is discussed by diversified talent-training model and individualized education mode. Furthermore, industrial cooperation, interactive platform and virtual labs are provided both for teachers and students. The teaching model proposed in this paper can be used as reference for innovative and practical training and education for electrical engineering major.

\section{REFERENCES}

[1] X. Ruan, S. Jiang, and M. Zhu, "The mode of cultivating applicationoriented engineering talents in local universities," Research and Exploration in Laboratory, vol. 31, pp. 135-137, Feb. 2012.

[2] W. Yang, X. Peng, Y. Yang, and S. Chen, "On constructing diversified talent-training models in local engineering colleges," Journal of Guangdong University of Technology (Social Sciences Edition), vol. 6, pp. 22-24, Mar. 2006.

[3] Z. Wei, "Undergraduate tutorial system:history, situation and future," Shandong Higher Education, vol. 23, pp. 62-67, Oct. 2015.

[4] L. Ma, and K. Chen, "Research and practice on the mode of cultivating IUR-integrated innovative talents in engineering programs", Shandong Higher Education, vol. 16, pp. 36-41, Mar. 2015.

[5] P. Xu, L. Yu, J. Yang, M. Xiao, and X. Yao, "Construction and exploration of innovative experimental zone for training mode of talents in engineering colleges," Experimental Technology and Management, vol. 27, pp. 24-29, Oct. 2010. 